\title{
Medicine in stamps-Ignaz Semmelweis and Puerperal Fever
}

Pullardaki tıp-Ignaz Semmelweis ve Lohusalık Humması

\author{
Ahmet Doğan Ataman ${ }^{1}$, Emine Elif Vatanoğlu- Lutz², Gazi Yıldınm³ \\ 'Department of Medical History, Vienna Medical Faculty, Vienna, Austria \\ ${ }^{2}$ Department of Medical History and Ethics, Yeditepe University Medical Faculty, Istanbul, Turkey \\ ${ }^{3}$ Department of Obstetrics and Gynecology, Yeditepe University Medical Faculty, Istanbul, Turkey
}

\section{Abstract}

Puerperal fever was common in mid-19 ${ }^{\text {th }}$-century hospitals and often fatal, with mortality at 10\%-35\%. Ignaz Philipp Semmelweis was a Hungarian gynecologist who is known as a pioneer of antiseptic procedures. Semmelweis discovered that the incidence of puerperal fever could be drastically cut by the use of hand disinfection in obstetrical clinics. He is also described as the "savior of mothers" and "father of infection control". This paper provides an overview on the process of preventing puerperal fever and the life story of the physician behind this attempt, Ignaz Semmelweis, through philately.

(J Turkish-German Gynecol Assoc 2013; 14: 35-9)

Key words: Ignaz Semmelweis, puerperal fever, infection, history, philately

Received: 15 January, 2013

Accepted: 14 February, 2013

\section{Introduction}

Worldwide, sepsis is the cause of death in about 1400 people each day. Many of these people develop sepsis from infections acquired as patients while in hospital. Infections acquired in the hospital are called nosocomial infections. They are the most common complications of hospitalized patients, with $5-10 \%$ of patients in acute care hospitals acquiring at least one infection (1). Nosocomial infections occur in 2 million patients per year in the United States, causing 90.000 deaths and resulting in $\$ 4.5-5.7$ billion in additional patient care costs. Infection control is essential in order to limit the spread of these diseases. Cross-infection of patients by the contaminated hands of healthcare workers is a major method of spreading infectious agents. Hand hygiene is noted to be the single most important factor for infection control. Even today, hand washing is performed only one third to one half as often as it should be (2).

Ignaz Semmelweis (Figure 1) was the first physician in medical history who demonstrated that puerperal fever (also known as "childbed fever") was contagious and that its incidence could be drastically reduced by enforcing appropriate

\section{Ozet}

19. yüzyıl ortalarında, hastanelerde lohusalık humması oldukça sık görülen, \%10-35 arasındaki ölüm oranlarıyla genellikle fatal seyreden bir hastalıktı. Ignaz Philipp Semmelweis, antiseptik uygulamaların öncüsü olarak bilinen Macar jinekologtur ve jinekoloji kliniklerinde el dezenfeksiyonunun sağlanmasıyla birlikte lohusalık humması oranlarının düşürülebileceğini keşfetmiştir. Kendisi aynı zamanda "annelerin kurtarıcısı" ve "enfeksiyon kontrolünün babası" olarak da tanınır. Bu çalışma,filateli aracılığıyla lohusalık hummasının önlenmesi sürecine ve bu sirecin arkasındaki hekim olan Ignaz Semmelweis'ın hayatına genel bir bakıs sunmayı hedeflemektedir.

(J Turkish-German Gynecol Assoc 2013; 14: 35-9)

Anahtar kelimeler: Ignaz Semmelweis, lohusalık humması, enfeksiyon, tarih, filateli

Geliş Tarihi: 15 Ocak 2013

Kabul Tarihi: 14 Şubat 2013 hand washing by medical care-givers (3). Although hugely successful; Semmelweis' discovery directly confronted the beliefs of science and medicine in his time.

\section{Early Years}

Ignaz Semmelweis was born on July 1, 1818 in the Tabán, an area of Buda, part of present Budapest, Hungary (then part of the Austrian Empire). He was the fifth child of ten of the family of grocer Josef and Teresia Müller Semmelweis. Ignaz Semmelweis began studying law at the University of Vienna in the autumn of 1837, but by the following year, for reasons that are no longer known, he had changed to medicine. He was awarded his doctorate degree in medicine in 1844. After failing to obtain an appointment in a clinic for internal medicine, Semmelweis decided to specialize in obstetrics. Semmelweis was appointed assistant to Professor Johann Klein in the First Obstetrical Clinic of the Vienna General Hospital on July 1, 1846 (3) (Figure 2).

His duties were to examine patients each morning in preparation for the professor's rounds, supervise difficult deliveries, teach students of obstetrics and be 'clerk' of records. Maternity institutions were set up all over Europe to address

Address for Correspondence: Emine Elif Vatanoğlu- Lutz, Department of Medical History And Ethics, Yeditepe University Medical Faculty, Istanbul, Turkey 
problems of infanticide of illegitimate children. They were set up as gratis institutions and offered to care for the infants, which made them attractive to underprivileged women, including prostitutes. In return for the free services, the women would be subjects for the training of doctors and midwives (4). There were two maternity clinics at the Viennese hospital. The First

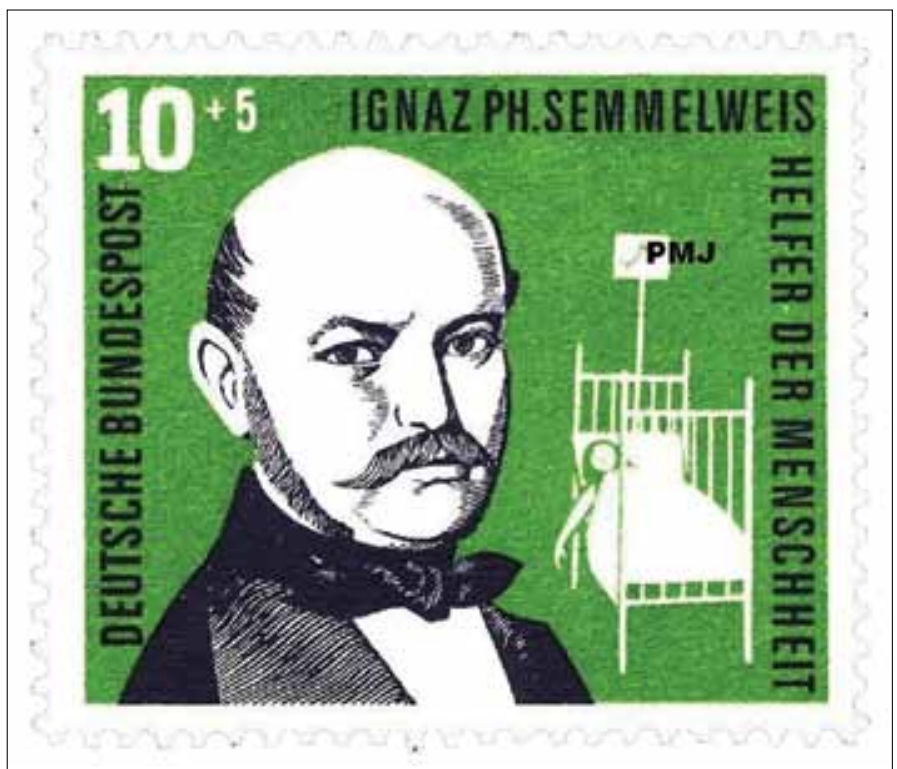

Figure 1. Semmelweis from the German series of welfare, which was issued in 1956

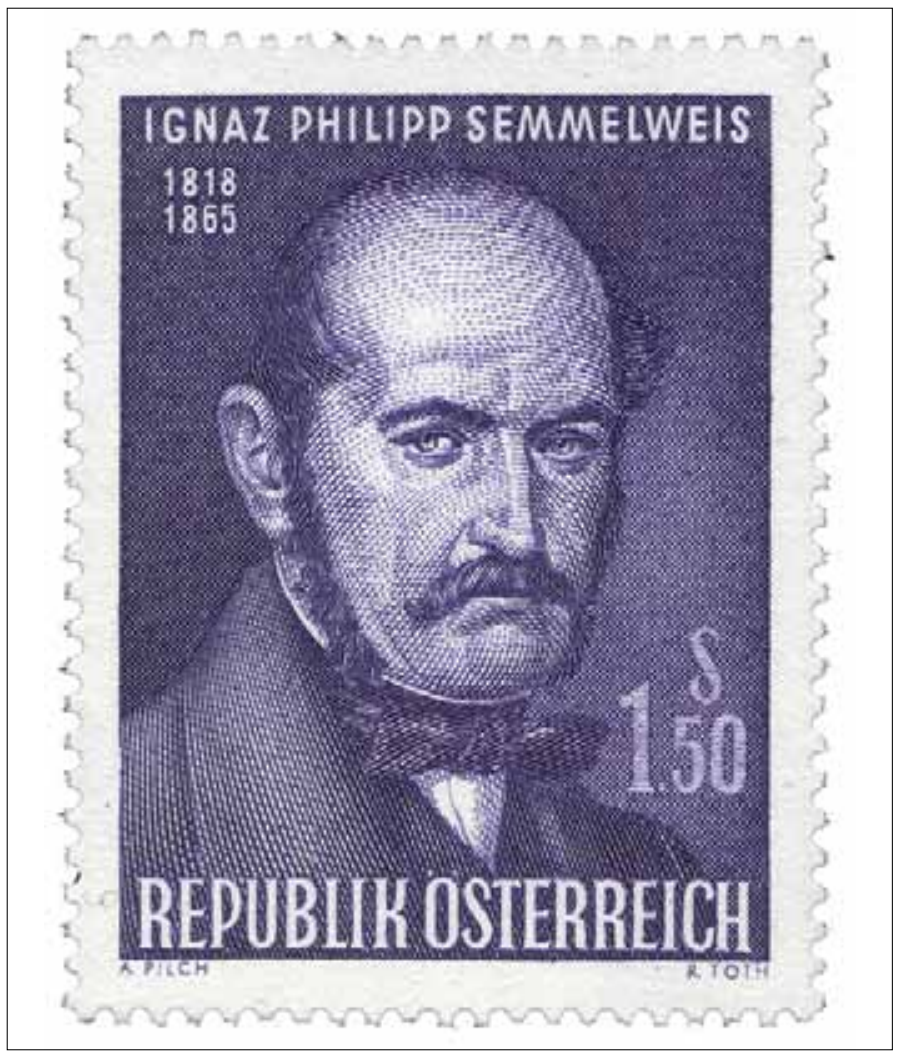

Figure 2. A stamp showing Semmelweis issued in Austria in 1965
Clinic had an average maternal mortality rate due to puerperal fever of about $10 \%$. The Second Clinic rate was considerably lower, averaging less than $4 \%$. This fact was known outside the hospital. The two clinics admitted on alternate days but women begged to be admitted to the Second Clinic, due to the bad reputation of the First Clinic. Some women even preferred to give birth in the streets, pretending to have given sudden birth, which meant they would still qualify for the child care benefits without having been admitted to the clinic. Semmelweis was puzzled that puerperal fever was rare among women giving street births. "To me, it appeared logical that patients who experienced street births would become ill at least as frequently as those who delivered in the clinic. What protected those who delivered outside the clinic from these destructive unknown endemic influences?"(5).

Semmelweis was severely troubled that his First Clinic had a much higher mortality rate due to puerperal fever than the Second Clinic. It "made me so miserable that life seemed worthless". The two clinics used almost the same techniques, and Semmelweis started a meticulous process of eliminating all possible differences, including even religious practices. The only major difference was the individuals who worked there. The First Clinic was the teaching service for medical students, while the Second Clinic had been selected in 1841 for the instruction of midwives only (3) (Figure 3).

\section{Prevention of Puerperal Fever}

He excluded "overcrowding" as a cause, since the Second Clinic was always more crowded and yet the mortality was lower. He eliminated climate as a cause because the climate was the same. The breakthrough occurred in 1847, following the death of his good friend Jakob Kolletschka, who had been accidentally poked with a student's scalpel while performing a postmortem examination. Kolletschka's own autopsy showed a pathology similar to that of the women who were dying from

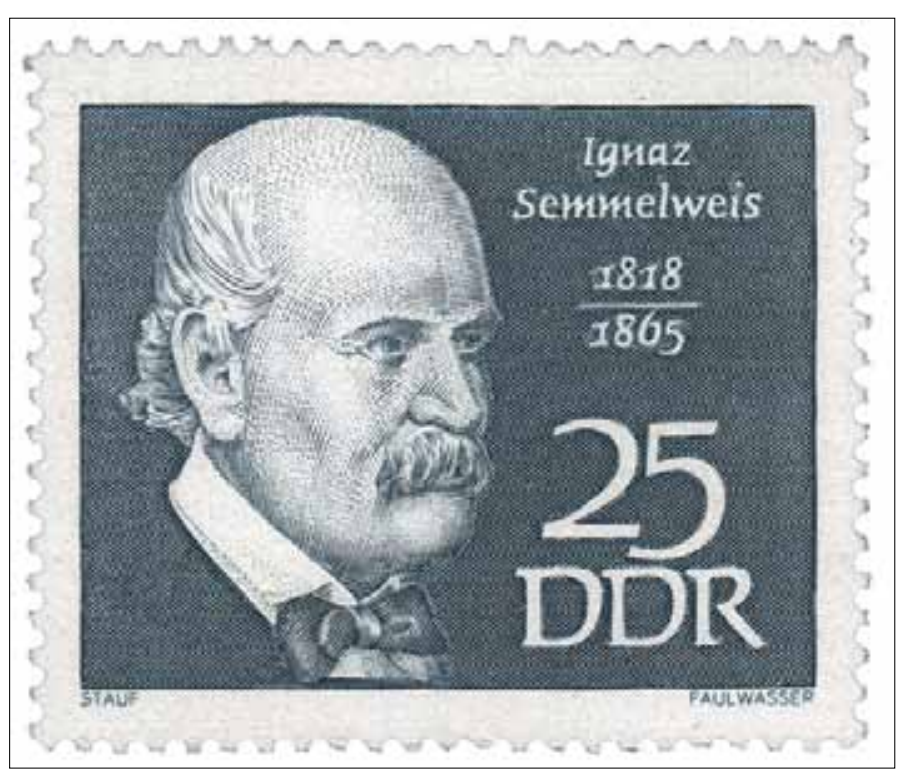

Figure 3. A stamp showing Semmelweis issued in East Germany in 1965 
puerperal fever. Semmelweis immediately proposed a connection between cadaveric contamination and puerperal fever (6). He concluded that he and the medical students carried "cadaverous particles" on their hands from the autopsy room to the patients they examined in the First Obstetrical Clinic. This explained why the student midwives in the Second Clinic, who were not engaged in autopsies and had no contact with cadavers, saw a much lower mortality rate (7).

Thus, Semmelweis concluded some unknown "cadaverous material" caused puerperal fever known as childbed fever. He instituted a policy of using a solution of chlorinated lime (modern calcium hypochlorite, the compound used in today's common household chlorine bleach solution) for washing hands between autopsy work and the examination of patients. He did this because he found that this chlorinated solution worked best to remove the putrid smell of infected autopsy tissue, and thus perhaps destroying the causal "poisonous" or contaminating "cadaveric" agent which were hypothetically being transmitted by this material (6).

The result was that the mortality rate in the First Clinic dropped $90 \%$, and was then comparable to that in the Second Clinic. The mortality rate in April 1847 was 18.3\%. After hand washing was instituted in mid-May, the rates in June were 2.2\%, July $1.2 \%$, August $1.9 \%$ and, for the first time since the introduction of anatomical orientation, the death rate was zero in two months of the year following this discovery (5) (Figure 4).

Semmelweis discovered that cases of puerperal fever, a form of septicemia, could be cut drastically if doctors washed their hands in a chlorine solution before gynaecological examinations. Semmelweis's observations conflicted with the estab-

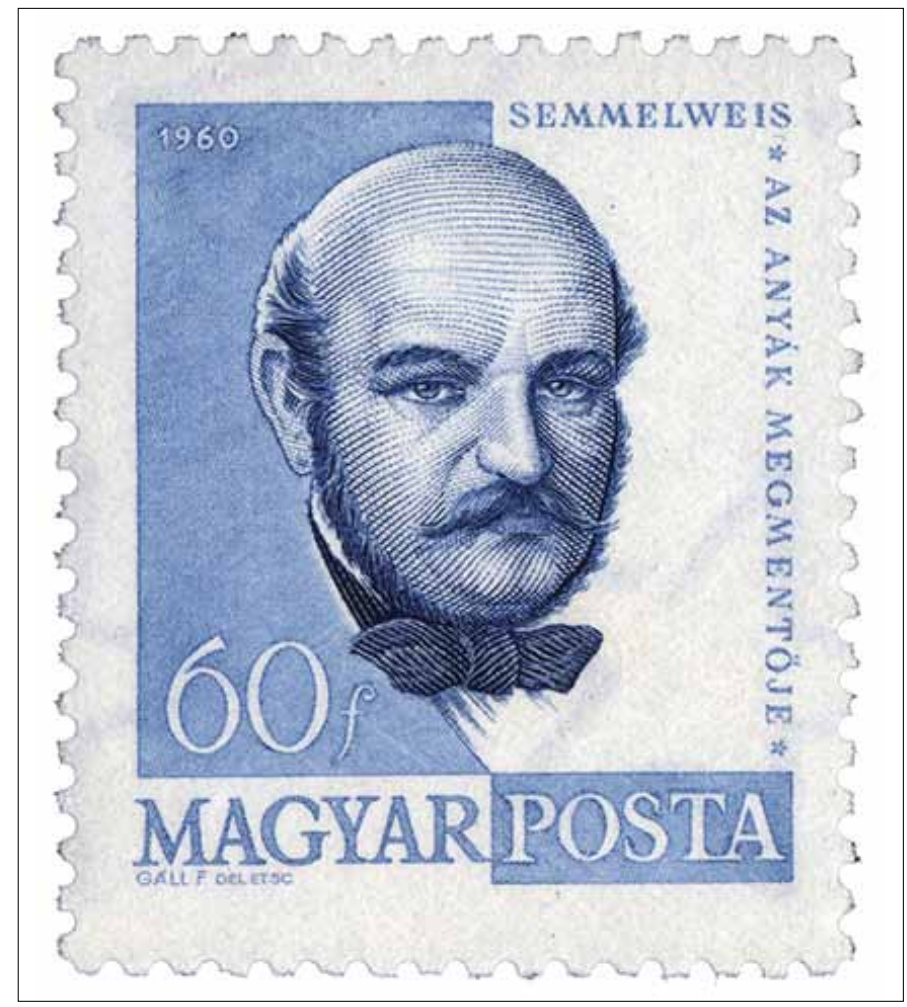

Figure 4. A stamp showing Semmelweis issued in Hungary in 1960 lished scientific and medical opinions of the time. The theory of diseases was highly influenced by ideas of an imbalance of the basic "four humours" in the body, a theory known as dyscrasia, for which the main treatment was bloodletting. His findings also ran against the conventional wisdom that diseases spread in the form of "bad air", also known as miasmas or vaguely as "unfavourable atmospheric-cosmic-terrestrial influences". Semmelweis's groundbreaking idea was contrary to all established medical understanding (4).

As a result, his ideas were rejected by the medical community. Other more subtle factors may also have played a role. Some doctors, for instance, were offended at the suggestion that they should wash their hands, feeling that their social status as gentlemen was inconsistent with the idea that their hands could be unclean (4).

In 1848, despite all these rejections, Semmelweis widened the scope of his washing protocol to include all instruments coming in contact with patients in labour, and used mortality rates time series to document his success in virtually eliminating puerperal fever from the hospital ward (5) (Figure 5).

\section{Personal Life}

Semmelweis had very difficult times especially after announcing his hand washing protocol and emphasising the importance of cleanliness. His claims were thought to lack scientific basis, since he could offer no acceptable explanation for his findings. Such a scientific explanation was made possible only some decades later, when the germ theory of disease was developed by Louis Pasteur, Joseph Lister, and others. In 1848 a series of tumultuous revolutions swept across Europe. The resulting political turmoil would affect Semmelweis's career. In Vienna on March 13, 1848, students demonstrated in favor of increased civil rights, including trial by jury and freedom of expression. The demonstration was led by medical students and young faculty members and were joined by workers from the suburbs. Two days later in Hungary, demonstrations and uprisings led to the Hungarian Revolution of 1848 and a full-scale war against the ruling Hapsburgs of the Austrian Empire. In Vienna,

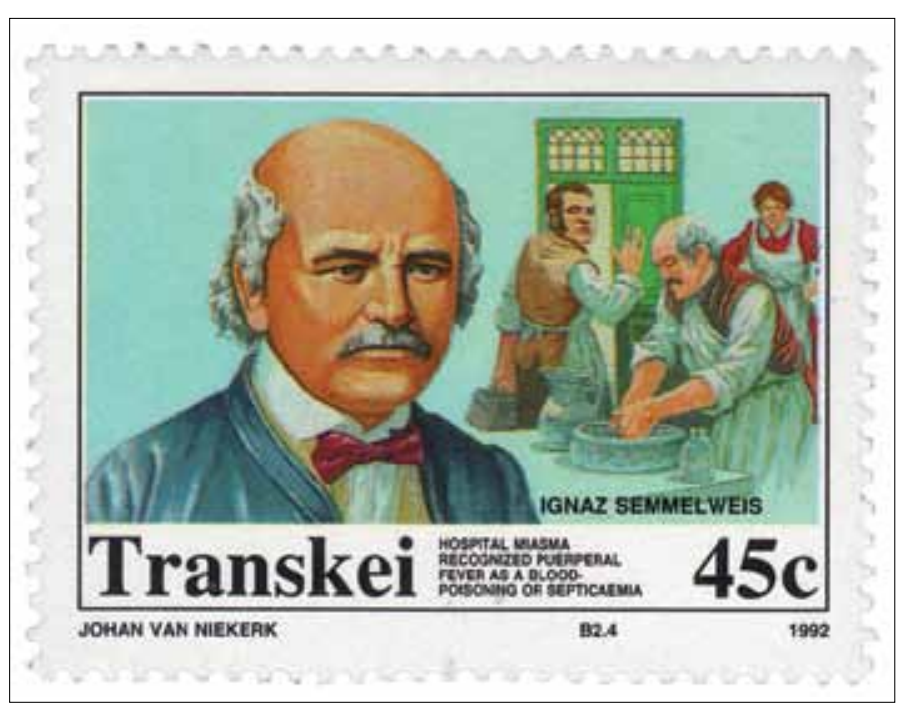

Figure 5. A stamp showing Semmelweis issued in Transkei in 1992 
the March demonstration was followed by months of general unrest (8) (Figure 6).

There is no evidence that Semmelweis was personally involved in the events of 1848. It is known that some of his brothers were punished for active participation in the Hungarian independence movement, and it seems likely that the Hungarian-born Semmelweis was sympathetic to the cause. Semmelweis's superior, Professor Johann Klein, was a conservative Austrian, probably uneasy with the independence movements and alarmed with the other revolutions of 1848 in the Hapsburg areas. It is known that Klein mistrusted Semmelweis. After having some serious personal conflicts with Klein, Semmelweis left Vienna abruptly and returned to Pest. In 1851, Semmelweis took the relatively insignificant, unpaid, honorary head-physician position of the obstetric ward of Pest's small St. Rochus Hospital. He held that position for six years, until June 1857. Childbed fever was rampant at the clinic and on a visit in 1850 , just after returning to Pest, Semmelweis found one fresh corpse, another patient in severe agony, and four others seriously ill with the disease. After taking over in 1851, Semmelweis virtually eliminated the disease. During $1851-1855$ only 8 patients died from childbed fever out of 933 births (0.85\%) (5).

Despite the impressive results, Semmelweis's ideas were not accepted by the other obstetricians in Budapest. The professor of obstetrics at the University of Pest, Ede Flórián Birly, never adopted Semmelweis's methods. He continued to believe that puerperal fever was due to uncleanliness of the bowel. Therefore, extensive purging was the preferred treatment (6). In 1857, Semmelweis married Maria Weidenhoffer (1837-1910) and they had five children (3).

In 1858, Semmelweis finally published his own account of his work in an essay entitled, "The Etiology of Childbed Fever". Two years later he published a second essay, "The Difference in Opinion between Myself and the English Physicians regarding Childbed Fever". In 1861, Semmelweis finally published his main work Die Ätiologie, der Begriff und die Prophylaxis des Kindbettfiebers (German for The Etiology, Concept and Prophylaxis of Childbed Fever) (7).

In his 1861 book, Semmelweis lamented the slow adoption of his ideas: "Most medical lecture halls continue to resound with lectures on epidemic childbed fever and with discourses against my theories. The medical literature for the last twelve years continues to swell with reports of puerperal epidemics, and in 1854 in Vienna, the birthplace of my theory, 400 maternity patients died from childbed fever. In published medical works, my teachings are either ignored or attacked. The medical faculty at Würzburg awarded a prize to a monograph written in 1859 in which my teachings were rejected (7) (Figure 7).

\section{Death}

In 1861, Semmelweis started to suffer from various nervous complaints. He suffered from severe depression and became excessively absentminded. He turned every conversation to the topic of childbed fever. It was impossible to appraise the nature of Semmelweis's disorder. It might have been Alzheimer's disease, a type of dementia, which is associated with rapid cognitive decline and mood changes. It might have been third stage syphilis, a then-common disease of obstetricians who

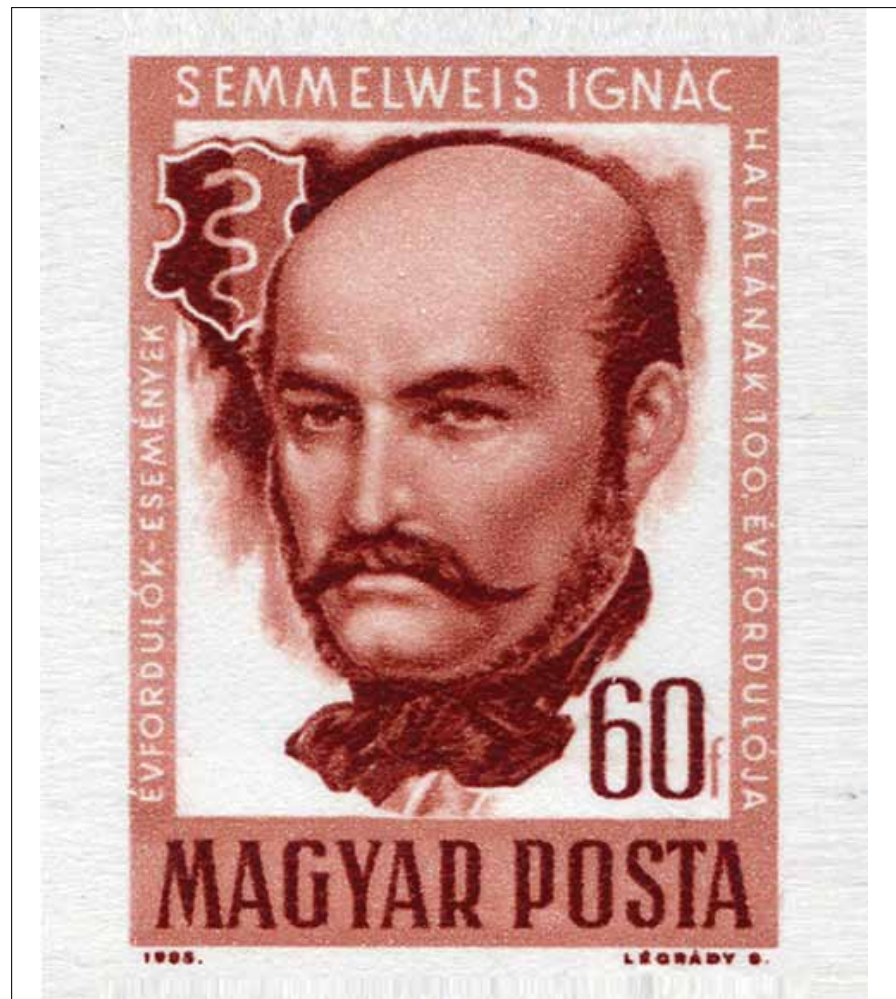

Figure 6. A stamp showing Semmelweis issued in Hungary in 1965

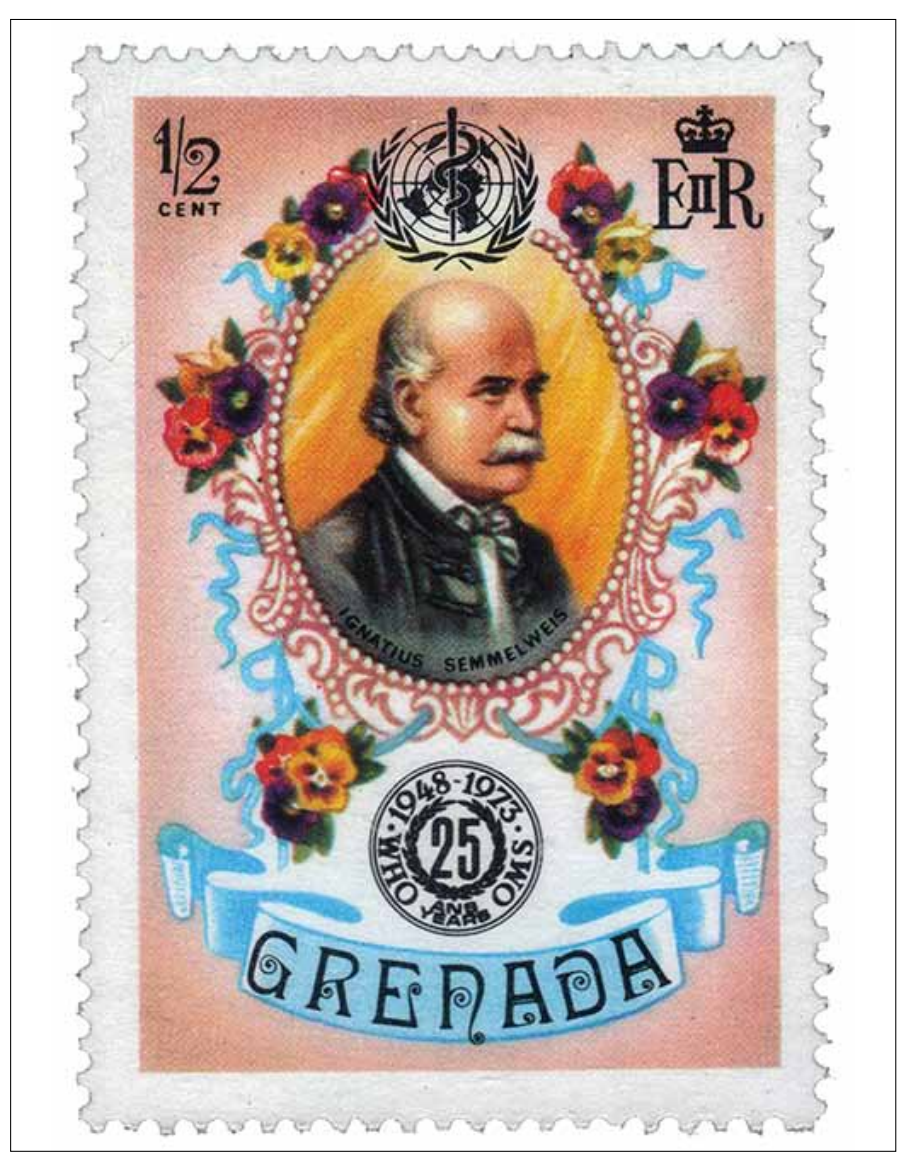

Figure 7. A stamp showing Semmelweis issued in Grenada in 1973 
examined thousands of women at gratis institutions. Or it might have been emotional exhaustion from overwork and stress. In 1865 , Semmelweis was referred to a mental institution (4). He died after two weeks in that clinic, on August 13, 1865, aged 47. Years after his death, especially with the discovery of germ theory and the nature of infectious agrnts, his great contribution to medicine was understood (5). Now, there is a university for medicine and health-related disciplines (located in Budapest, Hungary), called Semmelweis University and many other honorary establishments were organised after his name, like The Semmelweis Klinik, a hospital for women located in Vienna, Austria and The Semmelweis Hospital in Miskolc, Hungary. His house in Budapest is now a historical museum and a library called the Semmelweis Medical History Museum.

\section{Conflict of interest}

No conflict of interest was declared by the authors.

\section{References}

1. Gawande A. On washing hands. N Engl J Med 2004; 350: 1283-6. [CrossRef]

2. Burke JP. Infection control-a problem for patient safety. N Engl J Med 2003; 348: 651-6. [CrossRef]

3. Stewardson A, Allegranzi B, Sax H, Kilpatrick C, Pittet D. Back to the future: rising to the Semmelweis challenge in hand hygiene. Future Microbiol 2011; 6: 855-76. [CrossRef]

4. Rangappa P. Ignaz Semmelweis--hand washing pioneer. J Assoc Physicians India 2010; 58: 328.

5. Ellis H. Ignaz Semmelweis: tragic pioneer in the prevention of puerperal sepsis. Br J Hosp Med (Lond) 2008; 69: 358.

6. Jay V. Ignaz Semmelweis and the conquest of puerperal sepsis. Arch Pathol Lab Med 1999; 123: 561-2.

7. Daniels IR. Historical perspectives on health. Semmelweis: a lesson to relearn? J R Soc Promot Health 1998; 118: 367-70. [CrossRef]

8. Lange J. Ignaz Semmelweis--"Savior of Mothers". Long fight for recognition. Fortschr Med 1997; 115: 60. 